\title{
The influence of membranes on tests of coarse-grained materials at low cell pressures
}

\author{
L. Le Pen, J. Harkness, A. Zervos \& W. Powrie \\ University of Southampton, Southampton, Hampshire, United Kingdom
}

\begin{abstract}
In triaxial tests on small specimens of sands/silts and clays, cell pressures are usually greater than $100 \mathrm{kPa}$ and membranes are relatively thin $(\sim 0.3 \mathrm{~mm})$. In such tests the influence of the membrane on the stresses on the specimen is small and is usually ignored. Where cell pressures and/or the specimen strength are low the influence of the membrane increases. In such circumstances membrane corrections may be applied assuming right cylinder deformation and thin wall or circular hoop behaviour. However, there are circumstances in which these methods of membrane correction are invalid. For example when the material tested has a large particle size relative to the specimen diameter (e.g. $\mathrm{D}_{100}$ approaches $1 / 6$ of the specimen diameter) membranes behave neither as thin walls nor as circular hoops. Tests on railway ballast fall into this category; the large particles require larger specimens and thicker membranes. The thickness of these membranes is more significant as a proportion of specimen diameter and may have a greater influence on the stresses on the specimen. Furthermore, tests are often carried out at low cell pressures to replicate field conditions where membrane influence is greater. The influence of the membrane in such tests is investigated by means of discrete element method simulations using spherical particles in a face centred cubic packing. The membrane is modelled as an array of points surrounding the specimen and connected elastically. Using a closed form solution for the packing used, the influence of the membrane on initial specimen strength is quantified for differing membrane properties. Furthermore, as a first step to developing a way to correct for membrane influence on large grain sized physical specimens, parameters are identified that correlate to membrane influences.
\end{abstract}

\section{INTRODUCTION}

Membrane correction techniques for triaxial tests go back over half a century (Henkel \& Gilbert, 1952). However, in most cases their application is ignored on the basis that their effect is negligible because the effect of the applied cell pressure swamps the influence of the membrane. This is probably the case for the majority of triaxial tests carried out on clays, silts and sands. However, in tests on coarse aggregates at very low confining stress, membrane effects have a greater influence on the results and the basis for typically applied equations is not valid.

Prior to 1975, tests on large grain size materials were carried out mainly in the context of rockfills (e.g. Marachi et al., 1972, Zeller and Wullimann, 1957, Lowe, 1964, Frost, 1973, Leps, 1970). More recently, tests have been carried out on railway ballast (e.g. Raymond and Davies, 1978, Indraratna et al., 1998, Aursudkij et al., 2009, Anderson and Fair, 2008, Suiker et A1., 2005). For such tests, so that individual particles should not unduly influence the results, the maximum particle size is limited to no more than $1 / 6$ of the triaxial specimen diameter (Marachi et al., 1972). The more recent tests on railway ballast give a wide range in the reported values for peak effective angles of shearing resistance $\left(\phi_{\text {peak }}\right)$ as illustrated in Figure 1.

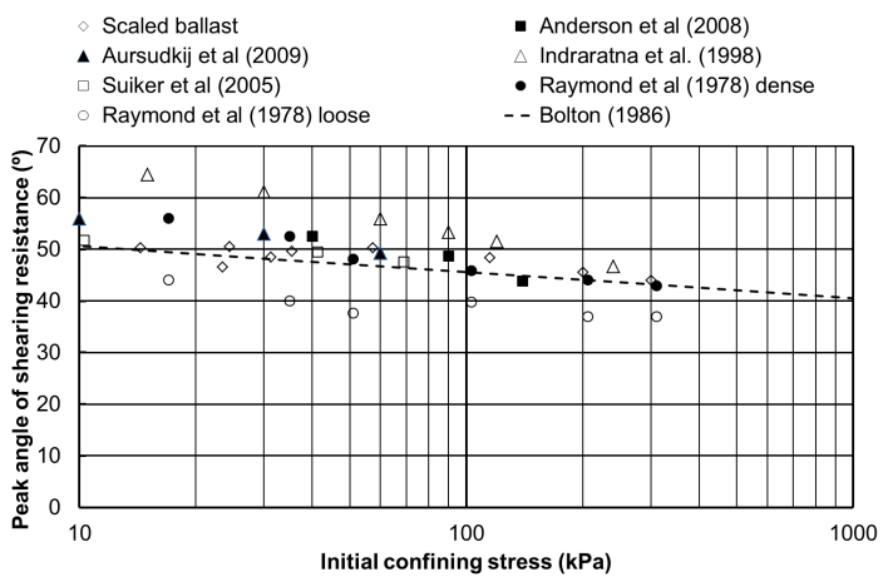

Figure 1. Peak strength vs initial confining stress for full size and $1 / 3$ scale railway ballast

Although it is possible that varying initial densities could be responsible for this, it is often not stated how or even whether membrane correction has been applied. A different possible explanation for 
the large range of reported values at lower confining stress could therefore be that different methods of membrane correction have been applied.

Also shown in Figure 1 are data from tests on a $1 / 3^{\text {rd }}$ parallel gradation of a granite ballast with the dashed line showing $\boldsymbol{\phi}_{\text {peak }}$ values calculated using the relationship proposed by Bolton (1986) (equation 1) for the $1 / 3$ scale material, based on $\phi_{\text {crit }}^{\prime}=36^{\circ}$, $\boldsymbol{e}_{\min }=0.71, \boldsymbol{e}_{\max }=1.00$ and $\boldsymbol{e}_{\boldsymbol{l}}=0.78$ found from laboratory testing.

$\phi_{\text {peak }}^{\prime}=3 \cdot\left(\frac{e_{\max }-e}{e_{\max }-e_{\min }}\right)\left(10-\ln p^{\prime}\right)-1+\phi_{\text {crit }}^{\prime}$

The dashed line in Figure 1 illustrates the commonly accepted trend probably first proposed by Leps (1970) that $\boldsymbol{\phi}_{\text {peak }}$ varies approximately linearly with the logarithm of the initial confining stress with the critical state strength as a lower limit.

This paper aims to investigate the angle of effective shearing resistance obtained from triaxial tests on coarse aggregates at low confining stresses by:

(1) Reviewing the basis for membrane corrections.

(2) Re-evaluating membrane behaviour for tests on large grain size materials such as railway ballast.

(3) Assessing the effect of the membrane in large grain size tests using DEM simulations on uniform arrangements of spheres and identifying parameters that could be used to correct membrane influence in physical tests.

\section{BACKGROUND}

\subsection{Membrane correction for stress}

Membrane correction equations for stress can be divided into two categories depending on whether they consider the membrane to (1) behave as a thin wall, or (2) buckle in the axial direction and behave as a series of unconnected hoops that confine the specimen. For approach 1 three principal publications (those of Henkel \& Gilbert, 1952, Duncan and Seed, 1967, Kuerbis and Vaid, 1990) set out equations of progressively increasing complexity. The underlying assumptions may be summarised as:

- Specimens deform as a right cylinder; the membrane acts as a thin wall that does not buckle.

- The membrane is elastic and incompressible.

- The membrane remains fixed to the platens.

- There are no initial stresses in the membrane. Applying the equations proposed by Kuerbis and Vaid (1990) and assuming the specimen undergoes only small volumetric strains typically results in a downward correction of the measured axial stress (as the thin wall supports the specimen) and little or no correction to the radial stress (as axial shortening makes material available for radial expansion.)
For approach 2, Henkel and Gilbert (1952) proposed a correction based on "hoop tension theory", for use when membrane buckling occurs. This always results in an upward correction to the externally measured radial stress as the test progresses and the membrane circumferential tension increases.

The consequence of both approaches is a reduction in the calculated mobilised shear strength of increased significance at lower confining stresses.

\section{TRIAXIAL TESTS ON SCALED BALLAST}

\subsection{Observed membrane shape}

Figure 2 shows a specimen of $1 / 3^{\text {rd }}$ scale parallel gradation of Network Rail ballast (a) being prepared within a $2 \mathrm{~mm}$ thick latex membrane and (b) after resin impregnation. The specimen was $150 \mathrm{~mm}$ in diameter $\times 300 \mathrm{~mm}$ high giving a ratio of largest particle size to specimen diameter of 1:7. In Figure $2 \mathrm{a}$ the specimen is held by internal suction maintained between $15 \mathrm{kPa}$ and $20 \mathrm{kPa}$. The Young's modulus in tension of the membrane was $1400 \mathrm{kPa}$, which is typical for latex membranes. It can be seen that owing to the relatively large particle sizes $(10 \mathrm{~mm}$ to 20 $\mathrm{mm}$ ), the membrane has an undulating surface and behaves as neither a thin wall nor a circular hoop. Following cyclic testing, a low viscosity epoxy resin was applied while maintaining a cell pressure of 45 $\mathrm{kPa}$. Figure $2 \mathrm{~b}$ shows that the resin has formed to follow the interior surface of the membrane, but has not coated the ballast particles in direct contact with the membrane which are still visible.

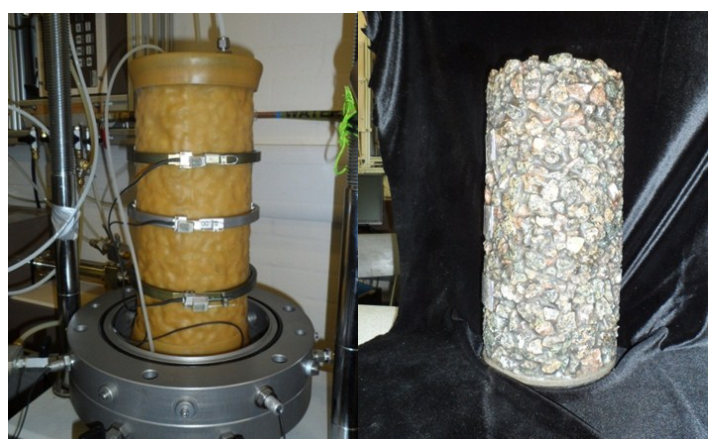

Figure 2. Triaxial specimen of $150 \mathrm{~mm}$ diameter $\times 300 \mathrm{~mm}$ high (a) being prepared, and (b) after resin impregnation.

The preserved specimen was then CT (Computer Tomography) scanned. An unfiltered reconstructed cross sectional slice is shown in Figure 3.

In Figure 3 the ballast particles are shown as light grey and the resin as dark grey. Some air holes are visible as black within the grey. The limit of the surrounding black shows the boundary with the membrane at $45 \mathrm{kPa}$ cell pressure. This is not circular; the membrane wraps onto the ballast where possible but indents into the voids between particles over significant lengths. 


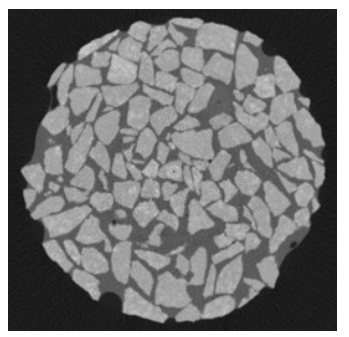

Figure 3. Cross section from CT scan of triaxial specimen

This type of behaviour was recognised by Molenkamp and Luger (1981) who evaluated the effect on volumetric strain measurements of the membrane penetrating into the voidspace; this may be referred to as either membrane penetration or membrane indentation. They recommended the use of a variety of theoretical and empirical relations, the choice depending on the ratios $\boldsymbol{t}_{\boldsymbol{m}} / \boldsymbol{D}$ and $\boldsymbol{\sigma} / \boldsymbol{E}_{\boldsymbol{m}}$ where $\boldsymbol{E}_{\boldsymbol{m}}$ is the membrane Young's modulus, $\boldsymbol{t}_{\boldsymbol{m}}$ is the membrane thickness, $\boldsymbol{\sigma}^{\boldsymbol{\prime}}$ is the cell pressure and $\boldsymbol{D}$ is the mean grain size. Only one of these relations is considered relevant here; it is based on an infinite plate and equal diameter particles spaced on a triangular grid, and is valid for $\boldsymbol{t}_{\boldsymbol{m}} / \boldsymbol{D}<0.2$ and large membrane deflections (i.e. $\boldsymbol{\alpha} / \boldsymbol{D}>0.2$, where $\boldsymbol{\alpha}$ is the indentation). In this case the penetration $(\alpha)$ normalised by the particle size $(\boldsymbol{D})$ can be expressed in terms of the void ratio $(\boldsymbol{e})$ and the Young's modulus and thickness of the membrane:

$\frac{\alpha}{D}=C(1+e)^{4 / 9}\left(\frac{D}{t_{m}}\right)^{\frac{1}{3}}\left(\frac{\sigma^{\prime}}{E_{m}}\right)^{\frac{1}{3}}$

where $\mathrm{C}$ is a constant in the range 0.15 to 0.4 .

Although Molenkamp and Luger (1981) mainly applied their study to membrane effects on the measured specimen volume, the mechanism of behaviour is equally valid for membrane effects on specimen stresses. The basis of this paper is that a relationship should exist between Equation 2 and an initial membrane effect that may be explored through DEM simulations. Furthermore careful analysis of the DEM data should identify parameters that can be measured in physical tests to calculate the evolution of membrane influence throughout the whole of the test.

\section{MEMBRANE BEHAVIOUR AND MODELLING}

\subsection{Conceptualised membrane behaviour}

Provided the membrane is either fixed at its contacts with the platens and/or has sufficient frictional resistance with the particles, at any given cell pressure it will penetrate into the void space. Depending on its properties, the membrane may then have sufficient stiffness to deform without having to come to rest on interior particles; this will result in tension in the membrane. This tension generates reactions against the supporting particles in the direction of the tangent to the membrane surface as it parts with the particles. Because these tangents are oriented at an angle to the initial right cylinder shape of the membrane, the tension can lead to both axial and radial additional stresses on the specimen. However the relative magnitudes of these and hence whether they lead to positive or negative errors in the measured axial and radial stresses and the mobilized shear strength are difficult to determine because, as will be shown, they vary with specimen strains.

\subsection{DEM implementation}

DEM simulations of a triaxial test were implemented using the code developed by Harkness (2009). Particles interact via frictional contacts with linear stiffness, and the equations of motion are integrated using an explicit scheme to yield particle positions and velocities. The top and bottom platens were modelled as planes and the membrane using a triangular finite difference mesh with about 34,000 elements, the resolution of which was chosen to capture with sufficient accuracy the membrane deformation in between and around the particles, as can be seen in Figure $4 \mathrm{a}$. The nodes at the ends of the membrane are attached to the platens. The remaining nodes are unconstrained, with the exception of nodes in contact with a particle; these are constrained to lie on the surface of the respective particle for as long as the particle/membrane frictional limit is not exceeded and the node is not pulled away from the particle. The confining pressure is converted to forces acting normal to the triangular elements, which are applied to the membrane nodes.

\subsection{Stress calculations}

The state of stress in the specimen can be calculated either externally, using the applied forces and the areas over which they act, or internally, using the detailed information on interparticle contact forces that DEM provides. This enables a comparison between the externally applied stresses and those received internally. In summary, the external stresses are determined (as in a standard physical test) as follows:

- The axial stress is the ram force divided by the area of the platen, which is updated throughout the test assuming right cylinder deformation.

- The radial stress is the cell pressure and is constant throughout each test.

The internal (DEM) stresses are then:

- The axial stress is the total force received by the particles in contact with the platen (including forces from the membrane that are transmitted through the membrane contact with the platen), divided by the area of the platen. This is updated 
throughout the test assuming right cylinder deformation.

- The radial stress is the radial force received by the internal boundary particles (including the radial forces from the membrane) divided by surface area of the right cylinder.

\section{DEM SIMULATIONS}

\subsection{Method}

To simplify the conceptual problem, DEM simulations have been run on uniform sized spheres in a face centred cubic packing, which is the densest possible. A specimen of spheres thus packed has an octagonal cross-section and the end platens were given octagonal shapes to match. Although the specimen has length dimensions these are best considered as relative ratios of the grain size. Also, because gravity is not applied in the simulations, they are essentially independent of absolute size.

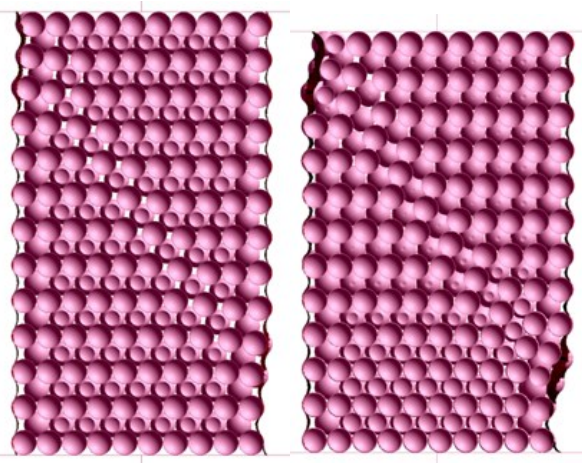

Figure 4. Section through DEM simulation showing development of failure

Figure 4 shows a typical DEM simulation failure mechanism. The specimen consists of $25 \mathrm{~mm}$ diameter particles and a $2.5 \mathrm{~mm}$ membrane, that is 450 $\mathrm{mm}$ tall and $250 \mathrm{~mm}$ wide. The applied confining stress is $10 \mathrm{kPa}$. Opposite sides of the specimen are 10 spheres apart so the particle size/specimen diameter ratio is $1: 10$. The indentation of the membrane along the perimeter between particles is apparent.

A series of simulations have been run as summarised in

\section{Table 1.}

Table 1. DEM simulations

\begin{tabular}{|c|c|c|}
\hline Confining & Membrane/particle & Membrane \\
\hline pressure $(\mathrm{kPa})$ & $\overline{\text { Ratios }}$ & $\mathrm{mm}$ \\
\hline $10,40,100$ & $1 / 10,2 / 15,1 / 5$ & $2.5,3.33,5$ \\
\hline
\end{tabular}

In each of these nine simulations other parameters were held constant as follows:

- Platen friction angle: $0^{\circ}$

- Membrane Young's modulus: $1400 \mathrm{kPa}$
- Local (non-viscous) damping coefficient: 0.3

- Interparticle friction angle: $25^{\circ}$

- Platen/particle normal stiffness: $1 \times 10^{7} \mathrm{~N} / \mathrm{m}$

- Platen/particle shear stiffness: $5 \times 10^{6} \mathrm{~N} / \mathrm{m}$

- Platen/membrane interface: fixed.

- Particle to membrane friction angle: $25^{\circ}$

The membrane thicknesses have been selected to correspond to both a range of values found in the literature for tests on coarse aggregates and to Molenkamp and Luger's (1981) particle to membrane thickness ratio for axial strain membrane behaviour.

A further advantage of using uniform spheres in face centred cubic packing is that, for rigid spheres with known surface friction, the initial angle of shearing resistance can be calculated using Equation 3 (Rowe, 1962)

$$
\frac{\sigma_{1}^{\prime}}{\sigma_{3}^{\prime}}=\tan (\alpha) \cdot \tan \left(\sigma_{\mu}+\beta\right)
$$

where $\sigma^{\prime}$ is the effective stress, $\sigma_{\mu}$ is the interparticle contact friction angle and $\alpha$ and $\beta$ are geometric properties of the packing $\left(63.5^{\circ}\right.$ and $45^{\circ}$ respectively). The solution is independent of the absolute value of confining stress as the ratio between the axial and cell pressure is always the same. For an interparticle friction angle of $25^{\circ}$, an initial angle of shearing resistance of $43.85^{\circ}$ is obtained. DEM simulations will result in a smaller angle of shearing resistance as the particles are not rigid and the medium is not infinite.

\subsection{Results}

Table 2 compares the peak angles of shearing resistance as external and internal values (see 4.3).

Table 2. DEM simulation results for peak strength

\begin{tabular}{llll}
\hline \multicolumn{2}{l}{ Test conditions } & \multicolumn{2}{l}{ Mobilised friction angle (degrees) } \\
$\begin{array}{l}\text { Stress/membrane } \\
(\mathrm{kPa})\end{array}$ & External & & Internal \\
\hline 10 & 2.5 & 40.3 & 40.0 \\
40 & 2.5 & 39.8 & 40.3 \\
100 & 2.5 & 39.1 & 40.1 \\
\hline 10 & 3.3 & 40.6 & 40.1 \\
40 & 3.3 & 39.9 & 40.2 \\
100 & 3.3 & 39.4 & 40.1 \\
\hline 10 & 5 & 41.1 & 40.2 \\
40 & 5 & 40.2 & 40.2 \\
100 & 5 & 39.7 & 40.1 \\
\hline
\end{tabular}

Owing to the particular nature of the dense lattice packing, the peak resistance occurs almost immediately at close to $0 \%$ axial strain. Both internal and external measurements give close to $40^{\circ}$. This compares reasonably well with the Rowe (1962) solution of $43.85^{\circ}$. Internal measurements show less scatter, although the external measurements are reasonably close as well. However, although superficially similar, the external results include large membrane in- 
fluences present both axially and radially that, at least initialy, act to cancel out each others influence on the mobilized shear strength. To illustrate the significance of membrane influences, results from the simulations with $10 \mathrm{kPa}$ cell pressure and $5 \mathrm{~mm}$ membrane are presented in Figures 5 to 8 .

Figure 5 compares the mobilized angle of shearing resistance determined from external and internal measurements. Initially there is little difference between the two but as the test progresses and the specimen fails over the second peak the external measures start to significantly overestimate (by up to $4^{\circ}$ ) the mobilized shear strength. This is significant because in tests on typical coarse aggregates (ballasts/rockfill), peak mobilized strength usually occurs somewhere between 3 and $8 \%$ axial strain, i.e within the range in which the external measures significantly overestimate the strength.

Figure 6 shows the additional radial and axial membrane stresses. The radial stresses increase throughout the test while the axial stresses generally reduce. Both show some reaction to the second peak in specimen strength ( $6 \%$ axial strain) and both are significant in relation to the externally applied stresses even at $0 \%$ axial strain.

Figure 7 compares the ratio of axial internal to external stresses to changes in strain ratio during the test (i.e. the change in radial strain/change in axial strain). There is clearly some correlation between these two parameters suggesting that the measured strain ratio in a physical test could be used to calculate the additional axial stress due to the membrane.

Figure 8 compares the radial strain and the radial stress ratio. This shows a strong correlation between the two suggesting that the measured radial strain in a physical test could be used to calculate the increase in radial stress due to membrane effects.

Table 3 compares the initial external and internal stresses for all the tests. Significant additional axial and radial stress result from membrane effects which increase with initial confining stress and membrane thickness.

Table 3. Comparison of initial stresses

\begin{tabular}{|c|c|c|c|c|c|}
\hline \multirow{2}{*}{\multicolumn{2}{|c|}{$\begin{array}{l}\text { Test conditions } \\
\text { Stress/membrane }\end{array}$}} & \multicolumn{4}{|c|}{ Initial stress values $(\mathrm{kPa})$} \\
\hline & & \multicolumn{2}{|c|}{$\sigma_{3}$} & \multicolumn{2}{|c|}{$\sigma_{1}$} \\
\hline$(\mathrm{kPa})$ & $(\mathrm{mm})$ & Ext & Int & ext & Int \\
\hline$\overline{10}$ & 2.5 & 10 & 11.2 & 10.6 & 13.5 \\
\hline 40 & 2.5 & 40 & 44.1 & 40.7 & 49.1 \\
\hline 100 & 2.5 & 100 & 109.4 & 101.1 & 117.7 \\
\hline$\overline{10}$ & 3.3 & 10 & 11.5 & 10.9 & 13.9 \\
\hline 40 & 3.3 & 40 & 44.4 & 40.9 & 50.2 \\
\hline 100 & 3.3 & 100 & 109.7 & 100.8 & 119.6 \\
\hline$\overline{10}$ & 5.0 & 10 & 11.8 & 10.7 & 14.6 \\
\hline 40 & 5.0 & 40 & 45.0 & 41.0 & 52.1 \\
\hline 100 & 5.0 & 100 & 110.6 & 101.1 & 123.4 \\
\hline
\end{tabular}

However, while the absolute magnitudes of additional membrane stress increase with confining stress, their significance relative to the externally applied stresses decreases.

Figure 9 shows the calculated indentation ratio (Equation 2) plotted against cell pressure for the nine tests with three membrane thicknesses. The $C$ value used for the indentation ratio was 0.275 , i.e. the average of the range given by Molenkamp and Luger (1981). The secondary y-axis shows the negative of the relative initial axial stress ratio. The initial stress ratio is plotted as a negative to show the correlation of the indentation ratio to the confining stress. Figure 9 shows that the:

- thickest membrane has the lowest indentation ratio but the greatest influence on stress ratio;

- stress ratio and hence the influence of the membrane is greatest at lower confining stresses.

Figure 9 illustrates a possible relationship between the initial indentation ratio and the initial additional membrane stresses that could be used to evaluate the initial membrane stresses in physical tests.

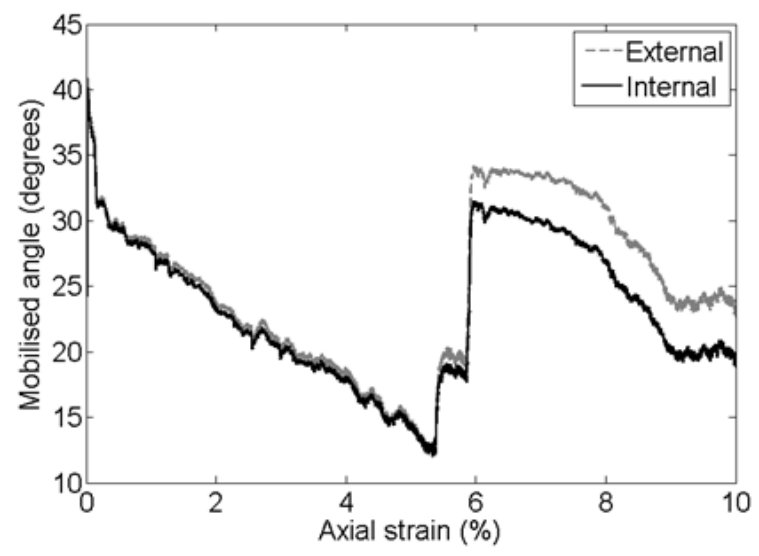

Figure 5. Mobilized friction from internal and external stress measurements; $10 \mathrm{kPa}$ confinement, $5 \mathrm{~mm}$ membrane

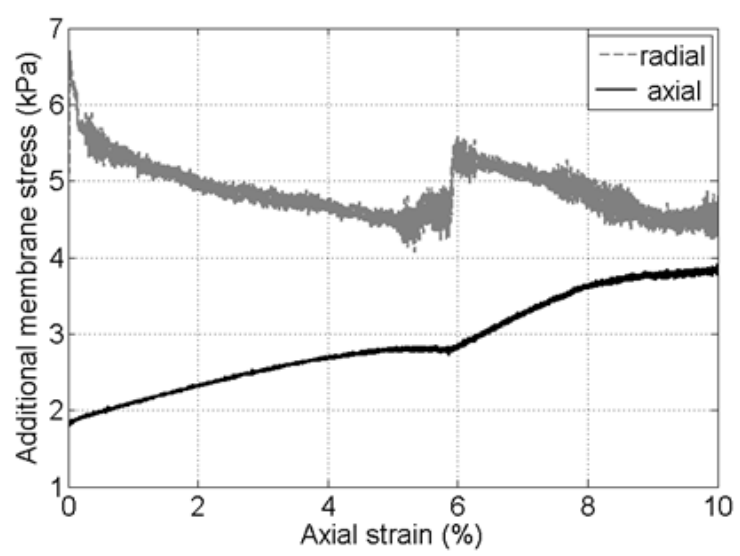

Figure 6. Additional membrane stress; $10 \mathrm{kPa}$ confinement, 5 $\mathrm{mm}$ membrane

\section{CONCLUSIONS}

By review of existing membrane correction approaches and comparison to the observed deformed membrane shape for tests on coarse aggregates it is concluded that:

- current approaches to membrane correction are not valid for coarse aggregates. 
In the case of the face centred cubic packing DEM simulations carried out it has been shown that:

- membrane behaviour leads to additional axial and radial stresses at zero axial strain (i.e. even before the test has begun).

- additional axial stress from the membrane correlates to the change in strain ratio.

- The additional radial stress correlates in proportion to the radial strain.

Further work is needed to evaluate whether these conclusions can be generalized to more typical random arrangements of differently shaped particles.

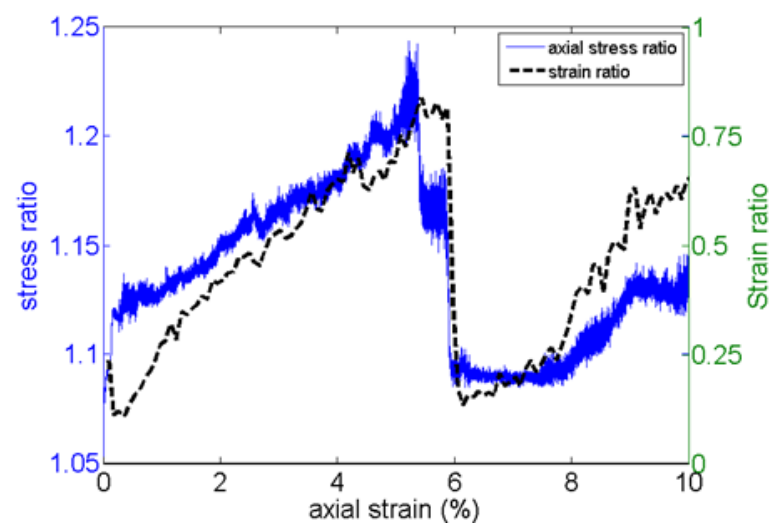

Figure 7. Axial stress ratio (internal to external) and change in strain ratio; $10 \mathrm{kPa}$ cell pressure, $5 \mathrm{~mm}$ membrane thickness

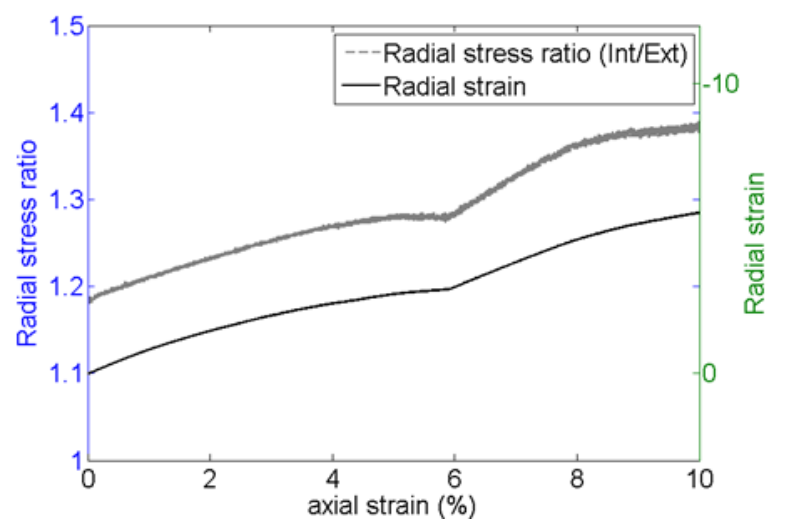

Figure 8. Radial stress ratio (internal/external) and radial strain; $10 \mathrm{kPa}$ cell pressure, $5 \mathrm{~mm}$ membrane thickness

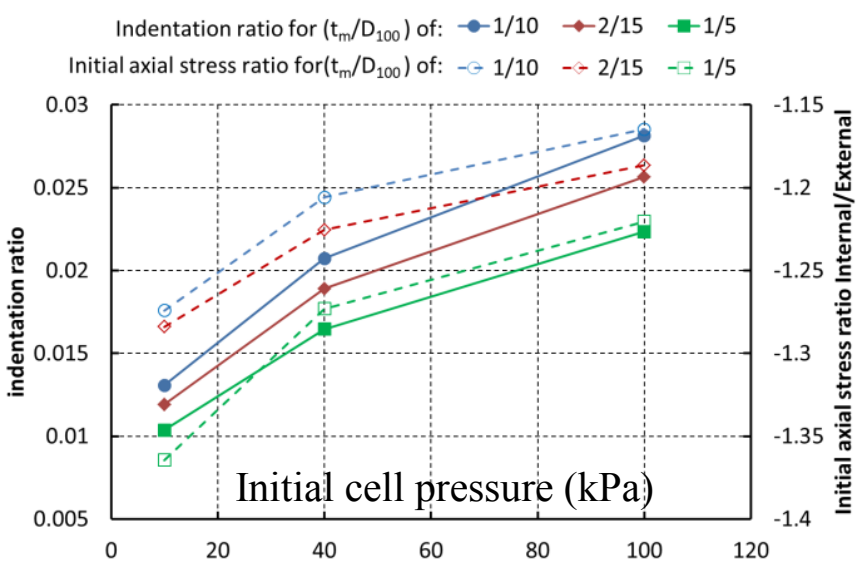

Figure 9: Relative indentation ratio and internal/external stress ratio against initial cell pressure

\section{REFERENCES}

Anderson, W. F. \& Fair, P. 2008. Behaviour of Railroad Ballast under Monotonic and Cyclic Loading. Journal of Geotechnical And Geoenvironmental Engineering, ASCE, Vol 134, 316 to 327.

Aursudkij, B., McDowell, G. R. \& Collop, A. C. 2009. Cyclic loading of railway ballast under triaxial conditions and in a railway test facility. Granular Matter, 11, 391 to 401.

Duncan, A. M. \& Bolton Seed, H. 1967. Corrections for Strength Test Data. Journal of Soil Mechanics and Foundations Division, Proceedings of the American Society of Civil Engineers, SM5, 121 to 137.

Bolton, M. D. 1986. The strength and dilatancy of sands. Geotechnique, 36, No. 1, 65 to 78 .

Frost, R. 1973. Some testing experiences and characteristics of boulder-gravel fills in earth dams. ASTM Special Technical Publication, 523, 207 to 233.

Harkness, J. 2009. Potential particles for the modelling of interlocking media in three dimensions. International Journal for Numerical Methods in Engineering, Volume 80, 1573 to 1594 .

Henkel, D. J. \& Gilbert, G. D. 1952. The effect of the rubber membrane on the measured triaxial compression strength of clay samples. Geotechnique, 3, 20 to 29.

Indraratna, B., Ionescu, D. \& Christie, H. D. 1998. Shear behavior of railway ballast based on large-scale triaxial tests. Journal of Geotechnical and Geoenvironmental Engineering, 124, 439.

Kuerbis, R. H. \& Vaid, Y. P. 1990. Corrections for Membrane Strength in the Triaxial Test. Geotechnical Testing Journal, Vol. 13, 361 to 369 .

Leps, T. M. 1970. Review of shearing strength of rockfill. Journal of Soil Mechanics and Foundations Division, Proceeding sof the American Society of Civil Engineers, Volume 96, 1159 to 1170.

Marachi, N. D., Chan, C. K. \& Seed, H. B. 1972. Evaluation of Properties of Rockfill Materials. Journal of the Soil Mechanics and Foundations Division, Proceedings of the American Society of Civil Engineers, 98, 95 to 114.

Molenkamp, F. \& Luger, H. J. 1981. Modelling and minimization of membrane penetration effects in tests on granular soils. Geotechnique, Volume 31, 471 to 486.

Raymond, G. P. \& Davies, J. R. 1978. Triaxial Tests on Dolomite Railroad Ballast. Journal of The Geotechnical Engineering Division, ASCE, 104, 737 to 751.

Rowe, P. W. 1962. The stress-dilatancy relation for static equilibrium of an assembly of particles in contact. Proceedings of the Royal Society of London. Series A, Mathematical and Physical, Vol. 269, , pp. 500 to 527.

Suiker, A. S. J., Selig, E. T. \& Frenkel, R. 2005. Static and Cyclic Triaxial Testing of Ballast and Subballast. Journal of Geotechnical and Geoenvironmental Engineering, $A S C E$.

Zeller, J. \& Wullimann, R. (1957) The shear strength of the shell materials for the Go-Schenenalp Dam, Switzerland. In Proc., 4th Inst. J on SMFE. London, 399 to 404. 